\title{
Dandy-Walker Syndrome: Management at Acharya Vinoba Bhave Rural Hospital, Wardha, India
}

\author{
${ }^{1}$ Harmandeep S Jabbal, ${ }^{2}$ Dhirendra D Wagh
}

\begin{abstract}
We discuss 10 cases of Dandy-Walker syndrome that presented between May 2014 and June 2015 at the Department of Neurosurgery and General Surgery in Acharya Vinoba Bhave Rural Hospital, Sawangi (M), Wardha, India. As the definitive surgical treatment protocol is not standardized, we discuss the different techniques used. Combined cystoperitoneal (CP) and ventriculoperitoneal (VP) shunt was done in three cases, two were treated with $\mathrm{CP}$ shunt alone, and the remaining five cases were managed with VP shunt.

Follow-up showed marked reduction in the head circumference and better motor development, along with alleviation of other neurological symptoms.

Seizures, hearing or visual problems, various central nervous system abnormalities, and systemic abnormalities were associated with poor intellectual development and could be used to predict intellectual outcome.

Prognosis varies due to several factors, but an early diagnosis and appropriate treatment have a good prognostic value.
\end{abstract}

Keywords: Dandy-Walker syndrome, Malformation, Management, Presentation, Prognosis, Rural Hospital.

How to cite this article: Jabbal HS, Wagh DD. Dandy-Walker Syndrome: Management at a Tertiary Care Hospital. Int J Recent Surg Med Sci 2017;3(1):20-24.

Source of support: Nil

Conflict of interest: None

\section{INTRODUCTION}

Dandy-Walker syndrome (DWS) is a rare congenital brain disorder characterized by a large posterior cranial fossa cyst, hypoplasia of the vermis, and elevation of the confluence of sinuses, and is usually (77-99\% of cases) complicated by hydrocephalus. ${ }^{1-5}$ The syndrome represents several abnormalities of the brain, which can be further classified as:

- Dandy-Walker malformation (DWM)

- Dandy-Walker variant, and

- Mega cisterna magna.

\footnotetext{
${ }^{1}$ Resident, ${ }^{2}$ Professor

${ }^{1,2}$ Department of General Surgery, Jawaharlal Nehru Medical College, Wardha, Maharashtra, India

Corresponding Author: Harmandeep S Jabbal, Resident Department of General Surgery, Jawaharlal Nehru Medical College, Wardha, Maharashtra, India, Phone: +918308192228 e-mail: harmandeep.s.jabbal@gmail.com
}

It was named by C. E. Benda (1954) after Walter Edward Dandy (1914) and Arthur Earl Walker (1942), who described the syndrome. ${ }^{6}$

It is a sporadic disorder with a prevalence rate of 1:30,000 live births in the United States, and accounts for approximately $7.5 \%$ cases of infantile hydrocephalus. ${ }^{7}$

The syndrome may appear dramatically or may develop unnoticed. The symptoms, which often occur in early infancy, include slow motor development and progressive enlargement of the skull. In older children, signs of raised intracranial pressure, such as irritability, vomiting, convulsions, and signs of cerebellar dysfunction may occur.

Large facial hemangiomas may have a distinctive group of associated arterial, central nervous system, and ophthalmologic anomalies. The acronym PHACE syndrome is used to emphasize the characteristic findings of this neurocutaneous syndrome: Posterior fossa malformations, hemangiomas, arterial anomalies, coarctation of the aorta and cardiac defects, and eye abnormalities. ${ }^{8}$

Treatment of DWS is not standardized. The preferred method for cases complicated by hydrocephalus is placement of a ventriculoperitoneal (VP) shunt. ${ }^{1}$ Other methods include excision of the ependyma by suboccipital craniotomy, cystoperitoneal (CP) shunt surgery, or combined VP and CP shunt. ${ }^{4}$

Due to the rare occurrence, varied presentations and different approaches to management are undertaken.

We aim to study

- Clinical presentation

- Management of DWS

- Prognosis

\section{MATERIALS AND METHODS}

We report 10 patients with DWS, all of whom presented in the outpatient department, between May 2014 and June 2015, with a common complaint of enlargement of the head and were admitted in the pediatric care.

After taking detailed history along with clinical examination, patients were subjected to routine hematologic and imaging investigations. Final diagnosis was made after confirmation on computed tomography (CT) or magnetic resonance imaging (MRI) brain. 


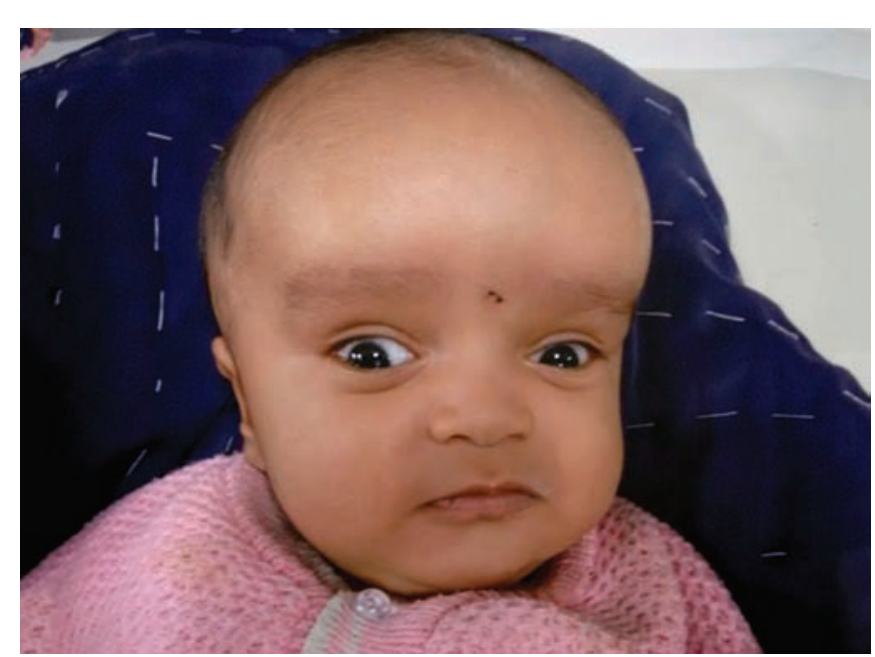

Fig. 1: Clinical picture - macrocephaly

Treatment was done based on absence/presence of hydrocephalus and its communication with the posterior fossa cyst.

\section{RESULTS AND DISCUSSION}

During the study period, 10 cases with DWS were identified; 7 out of 10 were males, in contrast to previous studies where cases of DWS were reported more in females. ${ }^{4}$

A total of 9 out of 10 cases in our study were below the age of 1 year, who presented with a common complaint of enlargement of the head. A total of 4 out of 10 cases presented with exclusive macrocephaly as evident in Figure 1.

A total of 6 out of 10 cases showed developmental delay in the form of slow motor development.

A total of 2 out of 10 cases had signs of raised intracranial pressure, such as episodes of convulsions, vomiting, and irritability.

The only noninfant, a 9-year-old male, was a known case of DWS diagnosed and operated in January 2014 with CP shunt. He presented with complaints of ataxic gait, sixth nerve palsy, and difficulty in verbalizing.

The gene locus for DWS is $3 q 24 .^{9}$ The DWS may result from chromosomal anomalies or environmental factors. ${ }^{10}$ Recognized chromosomal abnormalities associated with DWS include trisomies (trisomy 18, 13, 21, or 9) and triploidy. Recognized single-gene defects associated with DWS include Walker-Warburg syndrome or Meckel's syndrome, and, in these cases, the recurrence risk for siblings may be high. ${ }^{11}$

More recently, a first critical region associated with DWS, encompassing two adjacent zinc fingers in cerebellum genes, ZIC1 and ZIC4, has been identified. ${ }^{12}$ The presence of multiple congenital defects associated with DWM may shorten life span. ${ }^{9}$ Associated environmental factors include first-trimester exposure to rubella, cytomegalovirus, toxoplasmosis, or warfarin. Maternal diabetes during pregnancy is also associated with increased risk. ${ }^{11}$

The DWS is frequently associated with other central nervous system abnormalities including dysgenesis of corpus callosum, ectopic brain tissue, holoprosencephaly, and neural tube defects. ${ }^{13}$ Other associated abnormalities include heart defects, urogenital malformations, polydactyly or syndactyly, and abnormal facial features. No other congenital abnormality was detected in our cases.

Most cases of DWM are sporadic, whereas a small percentage of cases seem to run in families; however, DWM does not have a clear pattern of inheritance. ${ }^{11}$

Through the use of imaging tools (e.g., ultrasound, CT, MRI), DWS is typically diagnosed during antenatal period or before 1 year of age in approximately 76 to $80 \%$ of the cases. Historically, DWS was only found incidentally or during autopsy. ${ }^{21}$

The characteristic findings on MRI are (Fig. 2):

- Large posterior fossa cyst communicating with fourth ventricle

- Hypoplastic vermis

- Upward displacement of the falx tentorium and lateral sinuses

We used CT and MRI for diagnosis, which revealed 8 out of 10 cases consistent with DWS associated with hydrocephalus, of which 3 cases were obstructed due to aqueductal stenosis with no communication with the posterior fossa cyst, and 5 cases showed communication with posterior fossa cyst with variable patency of the aqueduct. A total of 2 out of 10 cases revealed a posterior fossa cyst with hypoplastic vermis, but no hydrocephalus. MRI Brain in our study revealed (Fig. 3):

- Dilatation of the ventricular system with cystic dilatation of the posterior fossa communicating (50\%)/ noncommunicating $(30 \%)$ with the fourth ventricle in $80 \%$ cases

- Nonvisualization or hypoplasia of vermis in $20 \%$ cases

- Upward displacement of the falx tentorium was evident in $30 \%$ cases

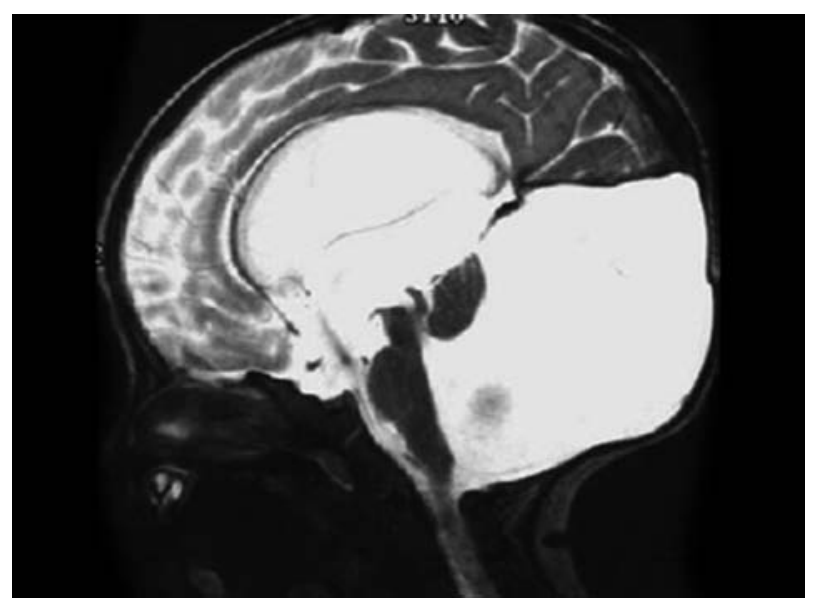

Fig. 2: Characteristic findings on MRI brain 

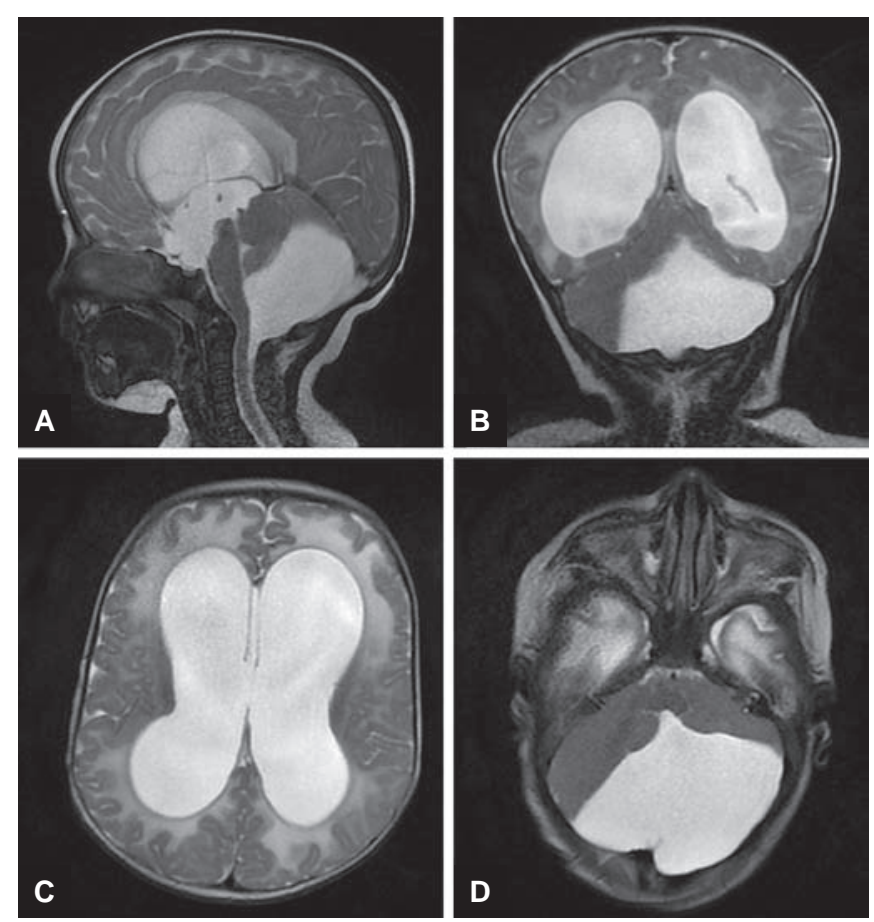

Figs 3A to D: Magnetic resonance imaging brain in our study revealed

\section{Treatment}

Dandy-Walker syndrome is generally treated surgically although medical management may be required for symptoms, such as seizures and vomiting.

Surgically, it is treated by one of four methods: Excision of the epithelium by suboccipital craniotomy, VP shunt surgery, CP shunt surgery, or combined VP and $\mathrm{CP}$ shunt surgery. ${ }^{4}$

The first method has a poor surgical record for children under the age of 2 or 3 years, as it is associated with high rates of recurrent symptoms and poor development of the child; hence, it is generally not applied. ${ }^{2,3,15}$

The VP shunt surgery is often performed in cases complicated by hydrocephalus, ${ }^{1}$ but the aqueduct constricts after VP shunt surgery. Therefore, the posterior cranial fossa cyst is not reduced and pressure in the posterior cranial fossa increases relatively, so $\mathrm{CP}$ shunt surgery may also be required.

In our study, 5 out 10 cases where hydrocephalus was communicating with the posterior fossa cyst were treated with VP shunt alone.

Combined VP and CP shunts have always been used. ${ }^{1,3}$ In our study, three cases, where there was no communication between the hydrocephalus and posterior fossa cyst, were treated with combined VP and CP shunts placement.

A total of two cases with exclusive posterior fossa cyst were treated with $\mathrm{CP}$ shunt alone (Figs $4 \mathrm{~A}, \mathrm{~B}$ and 5).

The preferred method of treatment may be $\mathrm{CP}$ shunt. ${ }^{16}$ However, due to its varied presentation, there is no standard treatment for DWS, which is complicated by hydrocephalus. ${ }^{17}$

Postoperatively, the children were managed in the Pediatric intensive care unit and wards.

\section{Prognosis}

Literature suggests that $40 \%$ individuals with DWM were normal intellectuals, while $40 \%$ had mental retardation and $20 \%$ were borderline. ${ }^{18}$

Cerebellum is believed to play a role in motor control, motor learning, and even cognition, such as development of language and other cognitive skills. ${ }^{19}$ Thus, the effect of DWS on intellectual development is variable, with some children having normal cognition and others never achieving normal intellectual development.

Paladini and Volpe, ${ }^{20}$ in 2006, demonstrated that the degree of vermian hypoplasia correlates significantly with the occurrence and severity of mental retardation. Thus, it seems that the more abnormal the vermis is, the poorer the prognosis will be (Figs 6 and 7).

In our study, the 9-year-old male showed marked improvement in the motor control, as the ataxic gait improved and he was able to walk normally. He also
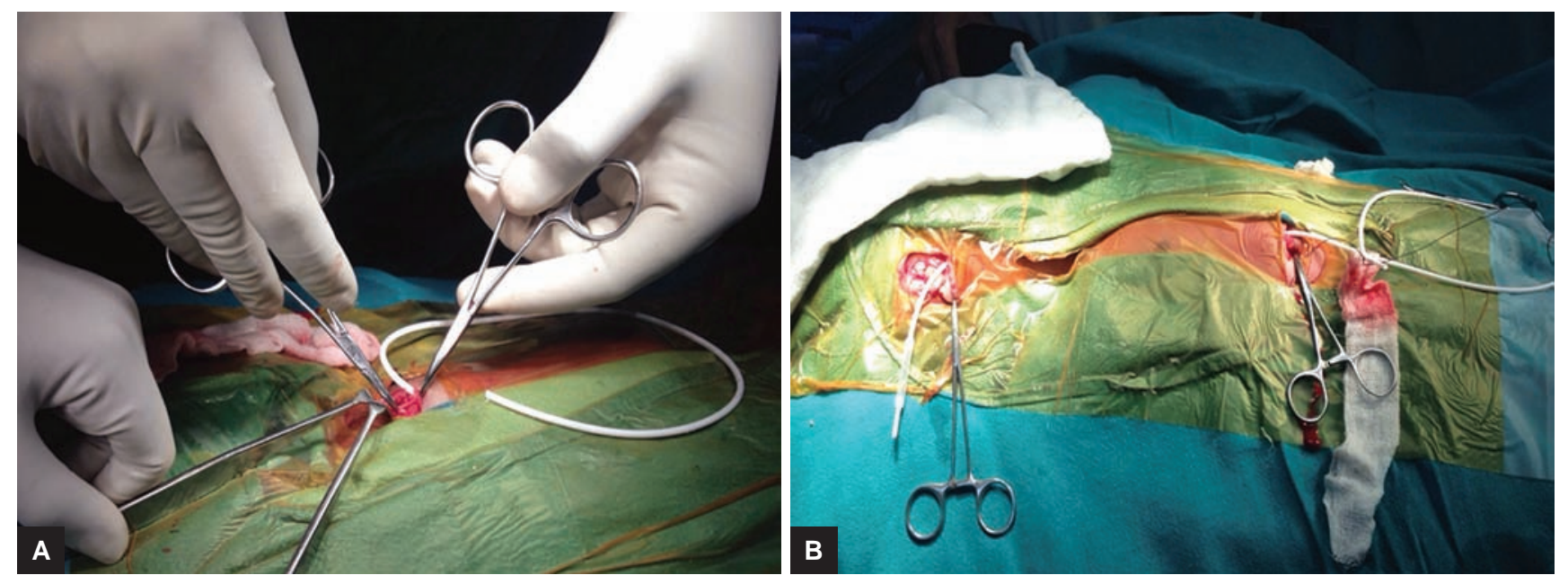

Figs 4A and B: Introduction of the abdominal catheter during VP shunting 


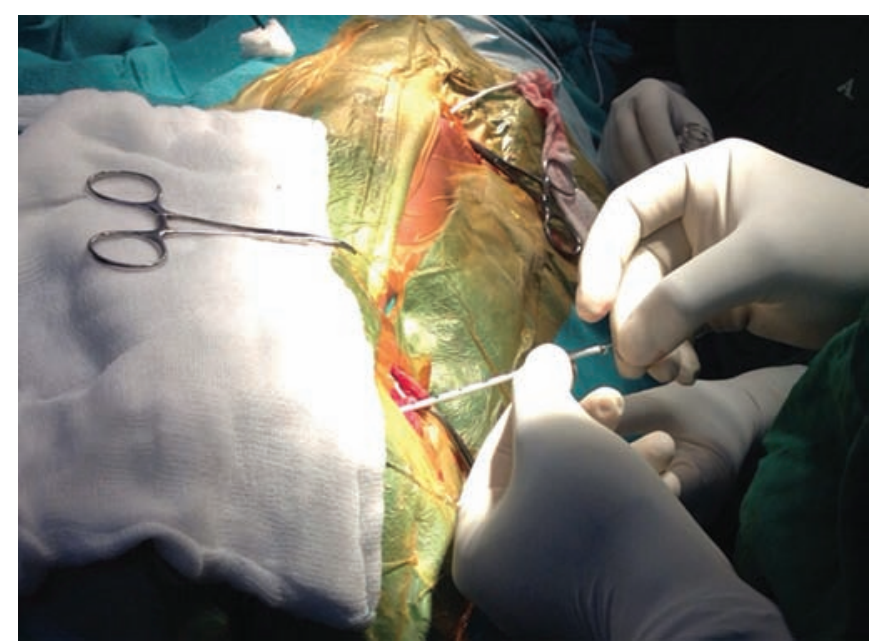

Fig. 5: Introduction of the ventricular catheter during VP shunting, abdominal catheter in situ is seen in the background
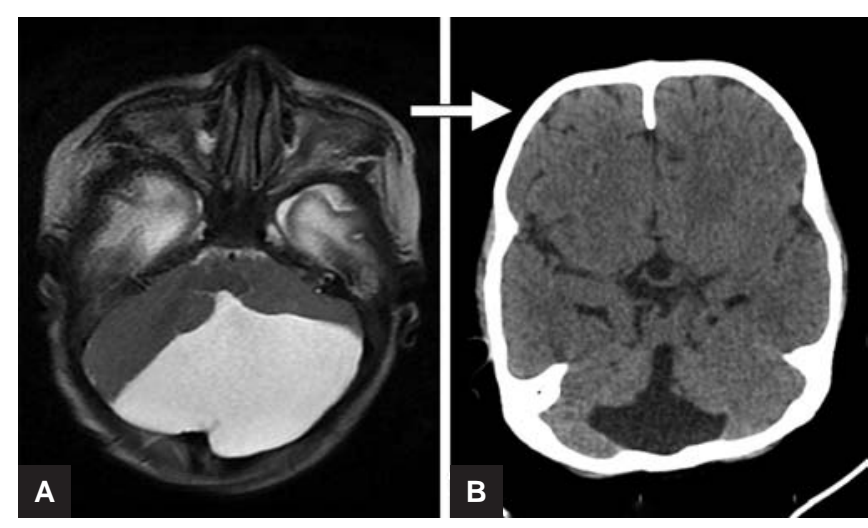

Figs 7A and B: Reduced size of the posterior cranial cyst postoperatively

showed improvement in verbalizing, wherein he could articulate words into sentences to form comprehendible speech.

A total of six out of nine infants were followed up during the study, none of whom showed any signs of neurological deterioration, but rather had normal developmental landmark features.

\section{CONCLUSION}

The DWS is a rare congenital brain abnormality, presenting usually in the first year of life with enlargement of the head. In older children, it can present with varied neurological symptoms. It is diagnosed with advanced imaging and treated primarily with CP or VP shunting or both. Prognosis varies due to several factors, but an early diagnosis and appropriate treatment have a good prognostic value.

\section{REFERENCES}

1. Bindal AK, Storrs BB, MacLone DG. Management of the Dandy-Walker syndrome. Pediatr Neurosurg 1990-1991;16(3): 163-169.

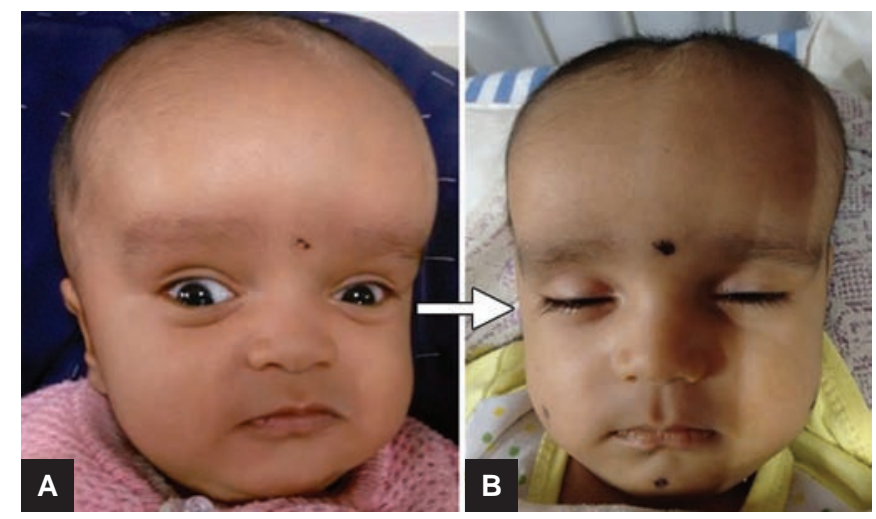

Figs 6A and B: Improvement in macrocephaly postoperatively

2. Hirsch JF, Pierre-Kahn A, Renier D, Sainte-Rose C, HoppeHirsch E. The Dandy-Walker malformation. J Neurosurg 1984 Sep;61(3):515-522.

3. Marinov M, Gabrovsky S, Undjian S. The Dandy-Walk syndrome: diagnostic and surgical considerations. Br J Neurosurg 1991;5(5):475-483.

4. Osenbach RK, Menezes AH. Diagnosis and management of the Dandy-Walker malformation: 30 years of experience. Pediatr Neurosurg 1992;18(4):179-189.

5. Peterson DI, Stirling K, Pena AM. Dandy-Walker syndrome without hydrocephalus in an adult. Bull Clin Neurosci 1983;48:115-121.

6. Bowen I, Standafer C, Krieger M. Dandy-Walker Syndrome in Children in: International Society of Pediatric Neurosurgery, Constantini S, Abbott R, editors. Retrieved 2014 Dec 5.

7. Luijkx T, Gaillard F. Dandy-Walker continuum. Radiopaedia Blog RSS; 2008. Accessed 2014 Nov 5.

8. Frieden IJ, Reese V, Cohen D. PHACE syndrome. The association of posterior fossa brain malformations, hemangiomas, arterial anomalies, coarctation of the aorta and cardiac defects, and eye abnormalities. Arch Dermatol 1996 Mar;132(3):307-311.

9. National Institute of Neurological Disorders and Stroke. Dandy-Walker syndrome information page; 2005 Feb [retrieved 2005 Jul 14]. Available from: http://www.ninds. gov/disorders/dandywalker.

10. Imataka G, Yamanouchi H, Arisaka O. Dandy-Walker syndrome and chromosomal abnormalities. Congenit Anom (Kyoto) 2007 Dec;47(4):113-118.

11. Genetics Home Reference. What is Dandy-Walker syndrome?

12. Notaridis G, Ebbing K, Giannakopoulos P, Bouras C, Kövari E. Neuropathological analysis of an asymptomatic adult case with Dandy-Walker variant. Neuropathol Appl Neurobiol 2006 Jun;32(3):344-350.

13. Correa GG, Amaral LF, Vedolin LM. Neuroimaging of Dandy-Walker malformation: new concepts. Top Magn Reson Imaging 2011 Dec;22(6):303-312.

14. Engelhard HH, Meyer JR. Adult-onset presentation of Dandy-Walker variant in siblings. Surg Neurol 1995 Jul;44(1): 43-47.

15. Lipton HL, Preziosi TJ, Moses H. Adult onset of the DandyWalker syndrome. Arch Neurol 1978 Oct;35(10):672-674.

16. Domingo Z, Peter J. Midline developmental abnormalities of the posterior fossa: correlation of classification with outcome. Pediatr Neurosurg 1996;24(3):111-118. 
17. Kalidasan V, Carrol T, Allcutt D, Fitzgerald RJ. The DandyWalker syndrome; a 10-year experience of its management and outcome. Eur J Pediatr Surg 1995 Dec;5(Suppl 1): 16-18.

18. Cardoso J, Lange MC, Lorenzoni PJ, Scola RH, Werneck LC. Dandy-Walker syndrome in adult mimicking myasthenia gravis. Arq Neuropsiquiatr 2007 Mar;65(1):173-175.
19. ten Donkelaar HJ, Lammens M, Wesseling P, Thijssen HO, Renier WO. Development and developmental disorders of the human cerebellum. J Neurol 2003 Sep;250(9):1025-1036. 20. Paladini D, Volpe P. Posterior fossa and vermian morphometry in the characterization of fetal cerebellar abnormalities: a prospective three-dimensional ultrasound study. Ultrasound Obstet Gynecol 2006 May;27(5):482-489. 